\title{
Exploring Gender Differences in Motivations for Using Sina Weibo
}

\author{
Ha Sung Hwang ${ }^{1}$, Eun Kyoung Choi $^{2}$ \\ ${ }^{1}$ Department of Media \& Communication, Dongguk University \\ Seoul, South Korea \\ [e-mail: hhwang@dongguk.edu] \\ ${ }^{2}$ Hanyang Peace Institute, Hanyang University \\ Seoul, South Korea \\ [e-mail: choice77@hanmail.net] \\ * Corresponding author: HaSung Hwang
}

Received November 3, 2015; revised January 18, 2016; accepted March 2, 2016; published March 31, 2016

\begin{abstract}
While Facebook and Twitter get worldwide attention, these popular SNSs are not available in China. As the leading local SNS, Sina Weibo has garnered much of the attention in China. The purpose of the study was to explore why Chinese college students use Sina Weibo and if gender differences exist in the motivations for using it. The results from a survey of 360 respondents show that Chinese students used Sina Weibo mainly for information-gathering, followed by accessibility to celebrity, social connection, self-presentation and entertainment. Among them the most dominant reason for using Sina Weibo was found to be informationgathering. This finding suggests that Sina Weibo functions as a platform to search for information on social issues and interests. The study also found that these motivations were significantly different between male and female users. Interestingly, female respondents used Sina Weibo much more broadly than male counterparts, accessing it to satisfy all needs such as information gathering, accessibility to celebrity, social connection, self-presentation and entertainment. Based on these findings limitations and direction for future studies are discussed.
\end{abstract}

Keywords: Sina Weibo, gender difference, motivation, Chinese SNS user

A preliminary version of this paper was presented at APIC-IST 2015, and was selected as an outstanding paper. 


\section{Introduction}

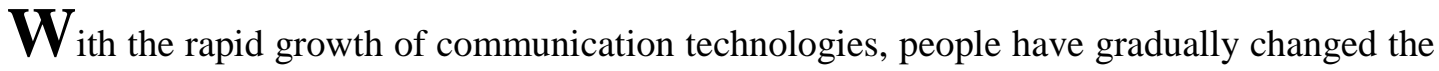
way that they interact with each other. One such change is the development of Social Networking Sites(SNS). SNS is generally defined as a web-based communication platform that aims to connect people and develop social contacts, by providing a venue for individuals to interact with friends and family members [1]. In recent years it has become a vital tool in personal and organizational activities.

Since Facebook was introduced in 2005, use of SNS has dramatically expanded worldwide. Facebook currently has 1.44 billion monthly active users, an increase of almost 165 million from March 2014. Twitter also grew by 47 million monthly active users over the past year, to 302 million. As market analysis suggests, Facebook and Twitter retain their position as the most popular SNS globally [2].

While Facebook and Twitter got worldwide attention, Sina Weibo has garnered much of the attention in China as Facebook since Twitter are not available there. In 2009 Chinese online media company SINA Corporation launched Sina Weibo, a Chinese microblogging website, and considered to be similar to Twitter or Facebook. By 2013, Sina Weibo had 503 million registered users, and almost 100 million messages were posted each day on Sina Weibo [3]. Over 30 percent of Chinese internet users use Sina Weibo, which is similar to Twitter in market penetration in the U.S. [4]. It is now one of the most popular sites in China and is also receiving attention overseas. Foreign celebrities too are using Sina Weibo as a communication channel to reach their Chinese audience.

With the rapid growth of SNS worldwide, there has been many academic researches on the topic as to why people use SNS. Individuals' reasons for joining SNS are that they want to share their interests, activities, personal stories, and make real-life connections [5]. Webbased SNS seemed to be ideal for sharing such information and experience. Thanks to technological development, SNS allows users to share ideas, pictures, posts, activities, events, and interests with people in their network and recommend them as well. These possibilities are what leads people to join SNS, allowing them to engage in social activities and increase social connenction.

However, Chinese citizens may have different motivations for using Sina Weibo, since Internet cencorship is quite common in China and Internet users are unable to access services such as Google, Facebook and Twitter [6]. According to Chinese law, certain posts with certain URLs or containing blacklisted keywords are not allowed on Sina Weibo [7]. Censorship also applies to posts on politically sensitive topics which are deleted via manual checks [8]. Such different social and political landscape can affect the user motivation in China. Nevertheless, there is little research on user motivation of Sina Weibo and how it compromises the fundarmental functions of SNS when the foreign SNSs are blocked.

It is also conceivable that the motivations for using Sina Weibo may differ between male and female users. The existing survey shows that more women than men tend to use SNS to connect with families [9]. In addtion, on Facebook women are more likely than men to view and share photos, keep in touch with friends, and post status updates [10]. Although one study explored gender differences in Sina Weibo use suggesting that women are more likely to use Sina Weibo to provide help and information to others, studies to date have not fully investigated gender differences in Sina Weibo usage [11].

In light of previous studies, this study attempts to explore why Chinese male and female 
students turn to incorporate Sina Weibo into their lives. It will also examine whether gender differences exist in using the site. Considering the important role of social media in relationship building in modern society, the objective of this study is to provide an empirical evidence on how and why users engage in SNS on the basis of different motivations of Sina Weibo users. Since previous literature is mostly focused on Facebook and/or Twitter which are popular globally other than in China, it seems that existing literature on SNS has not adequately explored usage of SNS in a non-Western setting. Therefore, this study fills a reserch gap by focusing on the most popular Chinese local SNS, Sina Weibo.

\section{Theoretical Background and Research Questions}

\subsection{Characteristics of Sina Weibo}

Microblogging service such as Twitter allows people to publish, share and discuss short messages on the Web. Since Twitter is not available in China, Sina Weibo is leading the microblogging market. Both services provide similar functions, allowing users to organize themselves in a follower-followee network, where people follow the message updates of other users [12].

Like Twitter, Sina Weibo allows users to post short 140 character messages on topics dealing with personal hobbies and interest to current affairs and politics [13]. It also allows users to upload video images and comment on the other user's posts. Users can follow others, repost Sina Weibos to their homepages, and broadcast their own Sina Weibos to followers. Additionally, users are also able to put emoticons and attach URLs, pictures, music and video files in the post.

However, Sina Weibo introduces a verification mechanism for individual users as well as organization accounts. Anyone can apply for a verification. To be verified, individual users must use a true photo as profile picture and a real name as a username when filling the appliaction form. The system then asks for personal information, such as residential and contact info, and occupation. Only when users submit this information, will the system finally approve the verification [14].

Moreover, there are "VIP" accounts on Sina Weibo. It is different from "verified accounts". The VIP accounts in Sina Weibo are only given to well-known celebrities (e.g., sports stars, singers and actors). When they get the official approval, a yellow " $V$ "' sign is shown against their names [15]. The VIPs have millions of followers and they are often recommended by the system to new users [16].

Such verification system has a significant influence on the usage of Sina Weibo. Studies suggest that verification system provides a way for the public to identify a trusted source, and for celebrities and organizations, it serves an official and reliable platform to promote themselves online [14]. A study found that messages that have pictures and those posted by verified users are more likely to reposted than those with unverified URLs [15]. Other studies compared the behaviors of verified users and unverified ones on Sina Weibo, and concluded that verifications stimulated SNS users to follow verified users and actively participate in the online social activities [14].

On Sina Weibo, Chinese express opinions about government and politics and it has diffused rapidly into society. Given the fact that the primary reason for using Sina Weibo is to seek information, Sina Weibo may facilitate a civic culture in the authoritarian state [13]. In fact, Zhao and Liu [17] studied the political influence of Sina Weibo, and indicated that Sina Weibo "provides people with an alternative communicative sphere for sharing 
previously suppressed, marginalized, "unofficial" memories as civil disobedience and accumulating them into an alternative collective memory that is relevant to the changing socio-political context of China”(p.41). This views Sina Weibo as a means of civic engagement and of mobilization of political contention.

\subsection{Motivations for using SNS}

Uses and Gratification Theory(UGT) proven to be valid theoretical appraoch appropriate for applying to the social media context [18]. Since the SNS emerged, many studies applied UGT. It is suitable to find the motivation of joing SNS and whether they satisfy particular needs. UGT provides a useful framework because it assumes that users are active in the choices of what communication channels in order to use to seek particular needs and certain channels are more effective than others in satisfying such needs. UGT is an individualcentered paradigm to understand the use of media and is based on the notion that media users are stimulated to engage with media to fulfill their pychological and social needs [19].

From the UGT perspective, studies have indicated that people join SNS primarily for seeking information, social connection and friendship, self-status, and entertainment [20, 21]. Similarly, in other study such motivations as social connection, shared identities, photographs, content, social investigation, social networking surfing, and status updates are identified [12]. Brandtzaeg and Heim found four major reasons for using SNSs in Norway: information, entertainment, social interaction, and peer-identity [22].

Some other studies focused on cultural differences in the usage patterns of SNS. For instance, Ji et. al, (2010) proposed five functions of SNS such as identity, expert search, connection, communication, and contents sharing. They also suggested that Korean and Chinese users mainly use the "search" and "connection" features while American users mainly use the communication fucntion to establish social bonding [23]. By using a sample of Korean and the U.S. college students, Kim, Sohn, Choi (2011) suggests that the major motivations for using SNS are seeking friends, social support, entertainment, information and convenience; and these motviations are similar between the two countries [24].

Since it has been reported that college-going users constitues a vast majority of SNS users [25], many studies have investigated the motivations for using SNS winthin the college sector. For U.S. college students SNS are used for social interaction with offline acquaintances in order to maintain friendships rather than make new friends [19]. Young adults primarily used Facebook to connect with friends whom they had a pre-established relationship offline [26]. These studies indicate that most popular reason for using SNSs was identified as social interaction. Becasuse SNSs provide a venue for college students to interact with others, the main purpose seems to keep in contact with friends and family and make new friends [27].

Although these findings from the prior research illuminate the important motivations for using SNS, most of them have focused on U.S. centric SNSs such as Facebook and Twitter, and little is known about China's leading microblogging service, Sina Weibo. There is scarce literature examining Sina Weibo. For instance, a study by Zhang and Pentina identified several important reasons for using Sina Weibo such as professional development, emotional release, informational seeking, citizenship behavior, self-expression, social connection, and visibility. The study concluded that Sina Weibo facilitates both self-expression and interactivity by serving as a platform for social connection, entertainment, as well as providing and seeking assistance [13]. In addition, Chinese motivations for using corporate SNS pages were identified for such purposes as information, entertainment and social integration [28]. 
According to the China Internet Network Information Center(CNNIC), in 2014, $72 \%$ of the total Sina Weibo users are aged from 20-35 and among them the majority of users are in their 20s and consitute the heaviest users. In light of these facts, this study aims to examine the usage of Sina Weibo within the college sector. Therefore, the following research question is proposed.

$R Q 1$. What are the motivations for using Sina Weibo among Chinese college students?

\subsection{Gender differences in motivations for using SNS}

A substantial amount of study has been carried out over recent years to study user demographics of SNS users. For example, age has been shown to affect social media use [9]. Youth are more likely to connect with friends and view and share pictures on Facebook than older users [13]. They also spend more time on Facebook and have more friends than older participants, while middle-aged and older adults are more likely to use social media as a tool to connect with people with common interests [13]. Also, it has been discovered that the youth use SNS such as Sina Weibo for self-promotion, possibly for professional or dating purposes [13].

On the other hand, previous research has identified a few differentiating factors that lead a male or a female user to use SNS services. Some studies suggest that there are different motivations for using SNS among men and women. A study from PEW research center shows that women are more likely to consume social media to connect with families than men [9]. Other study found that male SNS users reported using it for making new relationships while women reported more for relationship maintenance [27].

The usage patterns and motivation for using SNS by gender seems to be slightly different. Research on SNS indicates that motivations for information seeking, entertainment and selfexpression have a positive effect on male user's effective involvement; however, the motivations for socializing and entertainment have a positive effect on female users' effective involvement [11]. Other study found that female users were more likely to report greater overall use, and SNS use for communicating with peers, passing time and entertainment [29]. The study also found that male users more likely than females to report SNS use for social compensation and social identity gratifications.

A study by Special \& Li-Barber found that males and females differed in the overall level of self-disclosure and the type of information on their profile pages. On Facebook, males disclosed more basic information and more contact information than females [30]. In the Ukrainian sample, the study found that women are more likely to use Twitter for entertaining and social interaction, while men are more likely use it for professional development than women [31]. On the other hand, the study using the Australian sample reported that female Facebook users are more highly motivated by entertainment and information needs than male users [32]. The study concluded that these women are more likely to be Finders, moderate users who mainly use Facebook to satisfy the needs for information, as well as socializing, and entertainment. With regard to SNS specific behavior, research revealed that gender was a significant predictor of playing games indicating that men were more likely to report playing games more often than women [27].

There has been some investigation of gender difference in SNS use focusing on an Asian sample. For example, Lim (2014) identified 4 motivations for using SNS among Korean college students: information, self-status, interpersonal relationship and entertainment. The results however indicated that motivation were higher among female students and suggested 
that it may lead to SNS addiction among female students [33]. On the other hand, Kim (2012) found that men are more likely to use SNS for maintaining relationships than women in the Korean context [34].

As such research on gender differences in SNS use is emerging but still limited. A majority of previous work has focused on Facebook or Twitter, while there have been little examination of Sina Weibo. In addition, research into gender difference in motives for using Sina Weibo is insufficient. By analyzing the case of the 2010 Yushu earthquake, one study found that male users are more likey to talk about the latest social events than female users on Sina Weibo [15]. Based on the literature discussed above, the second research question is proposed:

RQ2: Are there differences in motivations for using Sina Weibo between male and female Chinese college students?

\section{Method}

\subsection{Sample and procedure}

College students are selected as the target sample in this study. The respondents were drawn from undergraduate students enrolled in campus-wide elective classes and communication classes at a large university in Beijing. The self-administered survey was developed in the Chinese language and was administered in October 2014. Participation in the study was voluntary. A total of 360 surveys were completed. The respondents' ages ranged from 18 to 23years old, with an average age of 20. Among the respondents $51.1 \%$ were male $(\mathrm{N}=184)$ and $48.9 \%$ were female $(\mathrm{N}=176)$. In terms of education level, $14.5 \%(\mathrm{~N}=83)$ were first year students, $17.95 \%(\mathrm{~N}=102)$ were second year students, $13 \%(\mathrm{~N}=74)$ were third year students and $15.5 \%(\mathrm{~N}=95)$ were fourth year students.

\subsection{Measures}

The questionnaire consisted of three primary sections. In the first section, the use of Sina Weibo was measured. The respondents were asked to report how long they have been using Sina Weibo and how much time they use Sina Weibo in a typical day. The second part of the questionnaire assessed the respondents the motives for using Sina Weibo. To measure user motivations for Sina Weibo, first, several motivation items used in previous research on SNS such as Sina Weibo, Twitter and Facebook were selected [13, 28, 29]. Next, a pilot study was conducted with 20 college students asking them to report the top three reasons for using Sina Weibo. The responses from the pilot study were combined with previous research and used to revise and modify the final list of motivations used in the survey. Through this process, new items were developed from the pilot study (e.g., to obtain knowledge about celebrities and to understand celebrities in-depth) and included in the survey. The final questionnaire consists of 21 motivation statements and respondents were asked to state their levels of agreement with the statement on 7-point scale (1: strongly disagree, 7: strongly agree). The last part of the questionnaire contained demographic questions such as gender, age, and educational level.

Approximately $75 \%$ of the respondents surveyed reported spending at least one hour per day on Sina Weibo. More than $80 \%$ reported they had been used Sina Weibo at least 2 years. Respondents were also asked how often they check Sina Weibo and on what types of devices. 
Unsurprisingly, $82.8 \%$ of respondents indicated that they check it either several times a day or constantly throughout the day. Most (93.4\%) used a personal cell phone to check Sina Weibo. Smaller numbers of respondents indicated that they checked Sina Weibo on a computer (6.6\%).

\section{Results}

\subsection{Motivations for using Sina Weibo}

The first research question concerns identifying motivations for using Sina Weibo. First, an exploratory principle component factor analysis with varimax rotation was conducted to determine motivations factors. After deleting four items due to low loadings or crossloadings five factors explaining a total of 73.58\% variance were identified. Table 1 shows the items retained for each factor along with their Eigenvalues, variance explained, and Cronbach's alpha (all above 0.80). The items for each factor were summed and averaged to create index factor scores for further analysis. The index of each factor was then tested with Cronbach's alpha to ensure inter-item reliability.

The first factor, "accessibility to celebrity" reflects Sina Weibo use to get information about celebrities by checking celebrities' daily life and retweeting and replying celebrities' postings. The second factor, "information gathering" manifests needs to find out what is going on in society, and to get information on social issue and events. "Social connection" factor ranges from the need to build new relationships, maintain friendship, to connect to friends those who they lost contact. "Self-presentation" factor includes such items as expressing opinion and feeling, posting pictures, and establishing user's identity. Finally, entertainment factor reflects the needs for releasing pressure, avoiding loneliness, passing time, and entertaining.

Next, the means of each factor were assessed to determine which motivations were salient for this respondent. The results show that majority of the respondents chose surveillance/information as the primary reason $(\mathrm{M}=5.27, \mathrm{SD}=1.24)$. Accessibility to celebrity was the another important reason for Chinese college students to use Sina Weibo $(\mathrm{M}=4.45, \mathrm{SD}=1.39)$, that is Chinese students used Sina Weibo to check daily life and recent status of celebrities, repost and reply their post, and communicate with them. Social connection ( $\mathrm{M}=4.29, \mathrm{SD}=1.04)$ was found to be the third most prevalent motivations for using Sina Weibo among the respondents. That is, Chinese students used Sina Weibo to maintain interpersonal connection, develop new relationships, and get in touch with friend they lost contact with. The least mentioned motivations were self-presentation ( $M=4.21$, $\mathrm{SD}=1.25)$ and entertainment $(\mathrm{M}=4.16, \mathrm{SD}=1.22)$.

Table 1. Motivations for using Sina Weibo among Chinese college students

\begin{tabular}{|l|l|l|l|l|l|l|}
\hline \multirow{2}{*}{ Motivations } & \multicolumn{5}{|l|}{ Factors } \\
\cline { 2 - 7 } & 1 & 2 & 3 & 4 & 5 \\
\hline Accessibility to celebrity & \multicolumn{5}{|l|}{} \\
\hline $\begin{array}{l}\text { To check the daily life and } \\
\text { recent state of celebrities }\end{array}$ & $\mathbf{. 8 3}$ & .08 & .04 & .06 & .01 \\
\hline $\begin{array}{l}\text { To retweet and reply } \\
\text { celebrities' posts }\end{array}$ & $\mathbf{. 8 2}$ & -.04 & .26 & .07 & -.00 \\
\hline $\begin{array}{l}\text { To understand celebrities in } \\
\text { depth }\end{array}$ & $\mathbf{. 8 2}$ & .11 & .54 & .01 & .16 \\
\hline
\end{tabular}




\begin{tabular}{|c|c|c|c|c|c|}
\hline $\begin{array}{l}\text { To discuss the issues of my } \\
\text { favorite celebrities }\end{array}$ & .80 & .08 & .04 & .35 & .17 \\
\hline $\begin{array}{l}\text { To get professional } \\
\text { knowledge about celebrities }\end{array}$ & .79 & .13 & .28 & .21 & .19 \\
\hline \multicolumn{6}{|l|}{ Information-gathering } \\
\hline $\begin{array}{l}\text { To find out what's going on } \\
\text { in society }\end{array}$ & .26 & .88 & .09 & .04 & .14 \\
\hline $\begin{array}{l}\text { To get information about } \\
\text { social issues that I am } \\
\text { interested in }\end{array}$ & .30 & .87 & .17 & .09 & .13 \\
\hline $\begin{array}{l}\text { To know social issues and } \\
\text { events around the world }\end{array}$ & .28 & .86 & .08 & .09 & -.03 \\
\hline To learn about the news & .24 & .71 & .02 & .10 & .12 \\
\hline \multicolumn{6}{|l|}{ Social connection } \\
\hline To build new relationships & .06 & .11 & .85 & .09 & .06 \\
\hline $\begin{array}{l}\text { To maintain relationships } \\
\text { already formed }\end{array}$ & .08 & -.02 & .83 & .13 & .07 \\
\hline $\begin{array}{l}\text { To exchange information with } \\
\text { friends }\end{array}$ & .07 & .00 & .82 & .10 & .13 \\
\hline $\begin{array}{l}\text { To get in touch with friends I } \\
\text { lost contact with }\end{array}$ & .19 & .05 & .76 & .19 & .13 \\
\hline \multicolumn{6}{|l|}{ Self-presentation } \\
\hline To express my opinion & .04 & .08 & .04 & .83 & .01 \\
\hline $\begin{array}{l}\text { To record my thoughts and } \\
\text { feeling }\end{array}$ & .17 & .00 & .05 & .82 & .05 \\
\hline To post pictures & .01 & .19 & .15 & .75 & .16 \\
\hline $\begin{array}{l}\text { To establish my personal } \\
\text { identity }\end{array}$ &. .15 & .11 & .04 & .83 & .11 \\
\hline \multicolumn{6}{|l|}{ Entertainment/relaxation } \\
\hline To release pressure &,- 00 & -.02 & .04 & .18 & .83 \\
\hline To relieve loneliness & .17 & .09 & .14 & .00 & .83 \\
\hline To pass time & .22 & .20 & .17 & -.03 & .67 \\
\hline Because it is entertaining & .20 & -.03 & .04 & .19 & .66 \\
\hline Eigenvalue & 9.57 & 2.79 & 1.89 & 1.70 & 1.03 \\
\hline Variance explained(\%) & 41.62 & 11.85 & 8.19 & 7.40 & 4.49 \\
\hline Cronbach’s alpha & .91 & .93 & .92 & .87 & .80 \\
\hline
\end{tabular}




\subsection{Gender differences in motivations for using Sina Weibo}

T-tests were performed to identify the difference between males and females in their reasons for using Sina Weibo. The results are summarized in Table 2. It was found that there were significant differences between female and male respondents in all motivations. Female Sina Weibo users were more likely than male users to use Sina Weibo for needs for accessibility to celebrities, information-gathering, social connection, self-presentation, and entertainment/relaxation.

Table 2. T-test of motivations for using Sina Weibo between males and females

\begin{tabular}{|l|l|l|l|l|}
\hline \multirow{2}{*}{ Motives } & \multirow{2}{*}{ T-value } & \multicolumn{2}{c|}{ Mean } & \multirow{2}{*}{ Sig. } \\
\cline { 3 - 4 } & & & Male(N=184 ) & Female(N=17 \\
$6)$ & \\
\hline Accessibility to celebrity & $-9.902^{* * *}$ & 3.81 & 5.11 & .000 \\
\hline Information-gathering & $-4.20^{* * *}$ & 5.0 & 5.55 & .000 \\
\hline Social connection & $-3.51^{* *}$ & 4.06 & 4.54 & .001 \\
\hline Self-presentation & $-4.93^{* * *}$ & 3.90 & 4.53 & .000 \\
\hline Entertainment/relaxation & $-6.36^{* * *}$ & 3.78 & 4.56 & .000 \\
\hline
\end{tabular}

\section{Conclusion and Discussion}

SNS is penetrating individuals' daily lives and transforming the way they express themselves, interact with each other, and perceive the world. Twitter and Facebook are the most popular worldwide SNS, while in China, Sina Weibo is the most widely used SNS. Chinese rely on Sina Weibo as a platform for sharing information, expressing opinions, or criticizing government policies, as the tightening of state control over the media.

Given that China has the world's most active social media users and 95\% of Internet users in major cities are registered on SNS [35], the purpose of the study was to examine why Chinese college students use Sina Weibo and if gender differences exist in the motivations for using it. The results show that Chines students used Sina Weibo mainly for information gathering purposes, followed by access to celebrity, social connection, self-presentation and entertainment. Respondents typically used Sina Weibo as a platform to seek information around the world and search for social issues and interests. Although this finding appeared to be consistent with prior studies suggesting that informational and social needs were the primary reasons for using SNS [13], it also reflected the distinctive social and political characteristics of China. SNS in China plays a more profound role as a platform for breaking news and political commentary which is not availble in the state-sanctioned news media [36]. It means that due to overly restrictive guidelines imposed by the Chinese government on social media, Sina Weibo is the only SNS available to the Chinese population for receiving news from a neutral perspective. In addition, given that the Chinese government blocked its citizens from accesing Facebook and Twitter, it seems logical that for college students in China, Sina Weibo has become an ideal place to receive information in all its richness. That said, Sina Weibo serves more as a news medium than a social network service.

Considering Sina Weibo enables users to access global information and news, the finding suggests that Sina Weibo serves as a platform to communicate with their favorite celebrities 
for college students in China as also pointed out by Chen [14]. She noticed that given the verification mechanism of Sina Weibo, the public identify true accounts of celebrities. In fact, this verification system builds trust and authenticity to the source and hence leads a larger portion of users in Sina Weibo [14].

On the other hand, consistent with an earlier research reporting that women and men perceive and use SNS differently, our results also show significant differences between male and female on the score across the 5 motivation scales [10]. Interestingly, the current study found that female users have higher mean scores for all motivations than male users. That is, females used Sina Weibo more for information gathering, and social connection purposes. Given that the ability to make connections to other people and to search social information are the core functions of a social network site, female users are more likely to seek these gratifications through Sina Weibo. In addition, findings suggest that female users are more likely to use Sina Weibo to satisfy the needs for getting access to celebrities (checking daily life, reposting and replying to posts), self-presentation (posting photos and expressing opinion and feeling), and entertainment. These results support prior research on SNS suggesting the women are more likely to provide information to others and women are more likely than men to keep in touch with friends $[12,28]$. Despite different measurements in motivations with different types of SNS, both early studies and this current study, draw a similar conclusion that there exists gender differences in motivations. Therefore, before we have a complete understanding of this finding, further investigation into gender differences online and users' cultural or value-based antecedents needs to be done.

Although the current study provided a general understanding of Sina Weibo use among Chinese students, several limitations and suggestions for future studies need to be addressed. The current study investigated younger educated Chinese, because they are the heaviest users of Sina Weibo. Therefore, the findings cannot be generalized to other demographic groups in China. Future studies should explore Sina Weibo motivations and uses using a random sample of the population, extend the research to other Asian countries, and explore motivations and uses of different SNSs. As Sina Weibo is undergoing dramatic growth, future research should consider other usage behavior, such as mobile and cross-platform use of Sina Weibo, and the role of various motivations in affecting their usage patterns.

Finally, the results of this study may have practical impliactions. First, considering Sina Weibo as a platform to access celebrity news around the world, this study can be meaningful for system practitioners to develop a unique and new service to reach foreign celebrities. Seond, such global celebrities may be a primary segment targeted by marketers. Utilizing Sina Weibo for the marketing pupose, market practioners may observe their potential customers and concentrate their efforts on that segment.

\section{References}

[1] J. Raacke and J. Bonds-Raacke, "Myspace and Facebook: Applying the uses and gratifications theory to exploring friend-networking sites," Cyberpsychology \& Behavior, vol. 11, no. 2, pp. 169-174, April, 2008. Article (CrossRef Link)

[2] D. Frommer, "Facebook is about to pass 1.5 billion active users-and 2 billion is within sight," Quartz, May 1, 2015. Article (CrossRef Link)

[3] J. Ong, "China's sina weibo grew 73\% in 2012, passing 500 million registered accounts," thenextweb.com, February 21, 2013. Article (CrossRef Link)

[4] Michelle and Uking, "Special: Micro blog's macro impact," China Daily, March 2, 2011. Article (CrossRef Link) 
[5] M. Han and B. Ahn, "A Study on the effects of motivations on attitudes toward advertisements : A focus on Sina Weibo,” The e-Business Studies, vol. 14, no. 3, pp. 155-174, August, 2013. Article (CrossRef Link)

[6] J. Lee, “Blocking gmail? We don’t know about it,” Yonhap News, December 30, 2014. Article (CrossRef Link)

[7] J. Kaiman, “Tiananmen Square online searches censored by Chinese authorities,” The Guardian, June 4, 2013. Article (CrossRef Link)

[8] Global Post, "Radiohead enters censored world of Chinese social media,” July 3, 2011. Article (CrossRef Link)

[9] A. Smith, "Why Americans use social media,” PewResearchCenter, November 15, 2011. Article (CrossRef Link)

[10] M. Foster, B. West and A. Francescucci, "Exploring social media user segmentation and online brand profiles,” Journal of Brand Management, vol. 19, no. 1, pp. 4-17, May 6, 2011. Article (CrossRef Link)

[11] M. Chun, "The affective/cognitive involvement and satisfaction according to the usage motivations of social network services,” Administration and MIS, vol. 31, no. 2, pp. 21-39, June, 2012. Article (CrossRef Link)

[12] A. N. Joinson, “'Looking at', 'Looking up’ or 'Keeping up with’ people? Motives and use of facebook," in Proc. of the SIGCHI Conference on Human Factors in Computing Systems, pp. 1027-1036, 2008. Article (CrossRef Link)

[13] L. Zhang and I. Pentina, "Motivations and usage patterns of weibo," Cyberpsychology, Behavior and Social Networking, vol. 15, no. 6, pp. 312-317, June, 2012. Article (CrossRef Link)

[14] J. Chen and J. She, "An analysis of verifications in microblogging social networks-sina weibo," in Proc. of Distributed Computing Systems Workshops (ICDCSW), pp. 147-154, June 18-21, 2012. Article (CrossRef Link)

[15] W. Guan, H. Gao, M. Yang, Y. Li , H. Ma, W. Qian, Z. Cao and X. Yang, “Analyzing user behavior of the micro-blogging website Sina Weibo during hot social events," Physica A: Statistical Mechanics and its Applications, vol. 395, pp. 340-351, February 1, 2014. Article (CrossRef Link)

[16] Y. Qu, C. Huang and J. Zhang, "Microblogging after a major disaster in China: A case study of the 2010 Yushu Earthquake," in Proc. of the ACM 2011 Conference on Computer Supported Cooperative Work, pp. 25-34, 2011. Article (CrossRef Link)

[17] H. Zhao and J. Liu, "Social media and collective remembrance: The debate over China's great famine on weibo," China Perspectives, vol. 1, pp. 41-48, 2015. Article (CrossRef Link)

[18] E. E. Hollenbaugh and A. L. Ferris, "Faceboook self-disclosure: Examining the roles of traits, social cohesion, and motives,” Computers in Human Behavior, vol. 30, pp. 50-58, 2014. Article (CrossRef Link)

[19] N. B. Ellison, C. Steinfield and C. Lample, “The benefits of Facebook 'friends:' Social capital and college students' use of online social network sites," Journal of Computer-mediated Communication, vol. 12, no. 4, pp. 1143-1168, July, 2007. Article (CrossRef Link)

[20] N. Park, K. F. Kee and S. Valenzuela, "Being immersed in social networking environment: Facebook groups, uses and gratifications, and social outcomes," CyberPsychology \& Behavior, vol. 12, no. 6, pp. 729-733, December, 2009. Article (CrossRef Link)

[21] Q. Gao, F. Abel, G. J. Houben and Y. Yu, “A comparative study of user's microblogging behavior on sina weibo and twitter," in Proc. of User Modeling, Adaptation, and Personalization Lecture Notes in Computer Science, vol. 7379, pp. 88-101, July 16-20, 2012. Article (CrossRef Link)

[22] P. Brandtzaeg and J. Heim, "Why people use social networking sites," in Proc. of Online Communities and Social Computing Lectures note on computer science, vol. 5621, pp.143-152, July 19-24, 2009. Article (CrossRef Link) 
[23] Y. G. Ji, H. Hwangbo, J. Yi, P.L.P. Rau, X. Fang and C. Ling, "The influence of cultural differences on the use of social netwrok services and the formation of social capital," International Journal of Human-Computer Interaction, no. 26, pp. 11-21, 2010.

Article (CrossRef Link)

[24] Y, Kim, D. Sohn and S. Choi, "Cultural difference in motivations for using social network sites: A comparative study of American and Korean college students," Computers in Human Behavior, vol. 27, pp. 365-372, January, 2011. Article (CrossRef Link)

[25] J. Kim and J. Lee, "The facebook paths to happiness: Effects of the number of facebook friends and self-presentation on subjective well-being," Cyberpsychology, Behavior and Social Networking, vol. 14, no. 6, pp. 359-364, November, 2010. Article (CrossRef Link)

[26] T. A. Pempek, Y. A. Yermolayeva and S. L. Calvert, "College students social networking experience on Facebook,” Journal of Applied Developmental Psychology, vol. 30, pp. 227-238, May-June, 2009. Article (CrossRef Link)

[27] N. L. Muscanell and R. E. Guadagno, "Make new friends or keep the old: Gender and personality differences in social networking use,” Computers in Human Behavior, vol. 28, pp 107-112, January, 2012. Article (CrossRef Link)

[28] L. R. Men and W. S. Tasi, "Beyond liking or following: Understanding public engagement on social networking sites in china,” Public Relations Review, vol. 39, no. 1, pp. 13-22, September, 2013. Article (CrossRef Link)

[29] M. Chan, X. Wu, Y. Hao, R. Xi, and T. Jin, "Microblogging, online expression and political efficacy among young chinese citizens: The moderating role of information and entertainment needs in the use of weibo," Cyberpsychology Behavior and Social Networking, vol. 15, no. 7, pp. 345-349, July, 2012. Article (CrossRef Link)

[30] W. P. Special and K. T. Li-Barber, "Self-disclosure and student satisfaction with Facebook," Computers in Human Behavior, vol. 28, pp. 624-630, March, 2012. Article (CrossRef Link)

[31] I. Pentina, O. Basnmanova and L. Zhang, “A cross-national study of Twitter users' motivations and continuance intentions,” Journal of Marketing Communications, pp. 1-20, January 20, 2014. Article (CrossRef Link)

[32] W. Shao, M. Ross and D. Grace, "Developing a motivation -based segmentation typology of Facebook users,” Marketing intelligence \& Planning, vol. 33, pp. 1071-1086, 2015. Article (CrossRef Link)

[33] M. Lim, "Gender differences on the effects of SNS use motivation and perceived interactivity and social anxiety in the SNS addiction proneness of college students," unpublished master's thesis, Konyang University, Korea, 2014. Article (CrossRef Link)

[34] H. Kim, "A study of use motivation of SNS and communication behavior," Journal of the Korea Academia-Industrial cooperation Society, vol. 13, no. 2, pp. 548-553, February, 2012. Article (CrossRef Link)

[35] C. Chiu, D. Lin and A. Silverman, “China’s social-media boom,” McKinsey \& Company, May, 2012. Article (CrossRef Link)

[36] L. Chen, D. Zhang and C. Wilson, "Tweeting under pressure: Analzing trending topics and evolving word choice on Sina Weibo," in Proc. of the first ACM Conference on Online Social Networks, pp. 89-100, 2013. Article (CrossRef Link) 


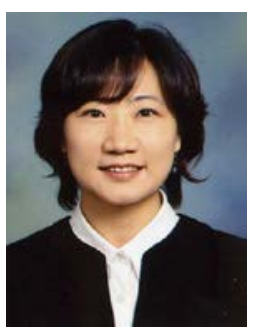

Ha Sung Hwang received her Ph.D. in Mass Media \& Communication at Temple University. She is currently associate professor of Media \& Communication at Dongguk University in Seoul, South Korea. Her research interests focus on social and psychological effects of communication technologies including SNSs and digital media. Email: hhwang@dongguk.edu

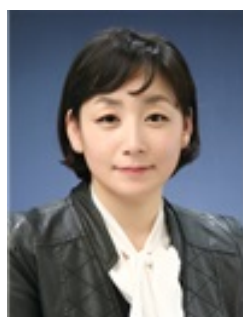

Eunkyoung Choi Ph.D. in Communication Studies from Loughborough University in the UK, is a research professor in Hanyang Peace Institute, Hanyang University. Her research interests include global media, broadcasting journalism and political economy of communications. Her recent research works are about cultural policy, digital media and culture.E-mail: choice77@hanmail.net 